УДК 621.313:621.314

\title{
Physical Basis of Quasi-optimal Seismoacoustic Pulse Generating for Geophysical Prospecting in Shallow Water and Transit Zones.
}

\section{Part 1. Theoretical foundations}

\author{
Danil S. Kudinov* \\ Oleg A. Maykov ${ }^{\dagger}$ \\ Institute of Oil and Gas \\ Siberian Federal University \\ Svobodny, 82, Krasnoyarsk, 660041 \\ Russia \\ Pavel V. Balandin $\ddagger$ \\ LLC Evenkiyageofizika \\ Republic, 173, Tyumen, 625023
}

Russia

Received 16.07.2019, received in revised form 01.11.2019, accepted 20.11.2019

Despite the development of alternative energy, hydrocarbon raw materials is one of the most important energy resources in the world. The discovery of new deposits today is an urgent task. Long-term prospects for the development of seismic exploration are associated with the development of the continental shelf, in particular the Arctic. Also, a large raw material potential is expected from poorly studied territories located on the Arctic coast of the Russian Federation, reef zones of the Persian Gulf states, and in the transit and shallow waters (at a depth of up to 10 meters).

The article discusses the theoretical aspects of the excitation of seismic waves in the water, addresses the problems of instrumental implementation of a new source of seismic vibrations that can work: in the water area, in tidal and coastal zones, i.e. produce continuous seismic profiling from the water area to the land. The scientific substantiation of the developed seismic source (SS) design is given.

Keywords: seismic source, seismic acoustics, pseudo-random sequence, shallow water, transit zone. DOI: 10.17516/1997-1397-2019-12-6-747-755.

\section{Introduction}

Environmental impact of traditional methods of exciting seismic vibrations in water using explosions and compressed-air sources have been studied extensively in the scientific works of ichthyologists and hydrobiologists. A number of studies have shown that the blast wave gives a negative impact on aquatic organisms [1].

The nature of the pressure waves propagation generated by the use of a pneumatic impulse differs from the excitation of seismic waves by means of a short-stroke impulse caused by the movement of the flat bottom of the float by electromagnetic (EM) force. In particular, single

\footnotetext{
*kudinovdanil@yandex.ru

† maykov_oleg@bk.ru

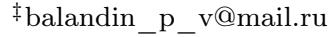

(c) Siberian Federal University. All rights reserved
} 
short pulse is generated with a duration of 1-10 ms [2]. In this case, an air bubble is not occurred, as during the operation of compressed-air sources (air-gun source). The air bubble gives the effect of instant expansion in the area of the air-gun source, which leads to a detrimental effect on aquatic biocenoses, and causes spurious oscillations which are interferences in the processing of seismic signals. In addition, the pulses emitted by the air-guns have a bad identity, i.e. the time and frequency domain characteristics of pulses differ from pulse to another [3]. Thus, for seismic exploration, the task of developing methods for exciting seismic waves which significantly reduce the level of negative acoustic impact on the ecosystem of reservoir supporting the ability to work in extreme shallow water (up to $1 \mathrm{~m}$ ), remains relevant [4].

It is expected that the use of a seismic source with an electromagnetic (electrodynamic) excitation principle will allow for coherent signal accumulation due to high amplitude and phase identity. This will ensure energetically optimal operation of the SS without using the maximum momentary power with a negative effect on aquatic biocenoses in the aquatic environment.

We define the basic data required to estimate the excitation of elastic oscillations and take several assumptions required for physical and mathematical justification of the seismic source:

1. The impact on the environment is a bipolar pulse which will increase the efficiency factor of the investigated seismic source by eliminating the process of "departure" of the reactive mass beyond the working gap between the ancor and inductor coil. Moreover, water is considered as an isotropic and incompressible medium [5].

2. The area of the base plate should be sufficient to provide a stroke to the medium in order to exclude the occurrence of cavitation processes in the zone of elastic oscillation generation. The force of influence should not exceed $P_{\max }=1 \mathrm{~kg} / \mathrm{cm}^{2}$.

3. Evaluation of the water attached mass makes it possible to optimize the duration of the seismoacoustic impulse with positive and negative polarity, as well as supply currents and voltages for more efficient matching of the SS and the propagation medium.

\section{Theoretical model of the motion of a base plate in a water medium}

There are many research is which has been carried out in the field of excitation of seismicacoustic waves for geophysical exploration [6-8]. However, for the technology of electromagnetic pulsed non-explosive excitation of elastic waves, this task is limited to research of electromechanical processes that occur in this system until the moment of transfer acustic energy the aquatic medium. Below we consider the movement of a plate in an aqueous medium under the influence of electromagnetic forces. For the physico-mathematical substantiation of processes in the aquatic environment when converting EM energy into mechanical energy we consider a generalized structural diagram of an electromagnetic seismic source (Fig. 1).

The SS includes a short-stroke EM drive which consists of an inductor with a magnetizing coil and an ancor mounted on a float of source. Between the poles of the inductor and the armature there is an air gap $\delta=4 \mathrm{~mm}$ and coil springs providing a prassing force within the gap equal to half the EM force $F_{\mathrm{EM}}$. The elastic coefficient of coil spring is chosen so that their compression force, within the range of 0-4 $\mathrm{mm}$ gap change, is constant $F_{0}=$ const. Under the influence of the excitation current $I$, the magnetizing coils excite a magnetic field, creating a attractive 


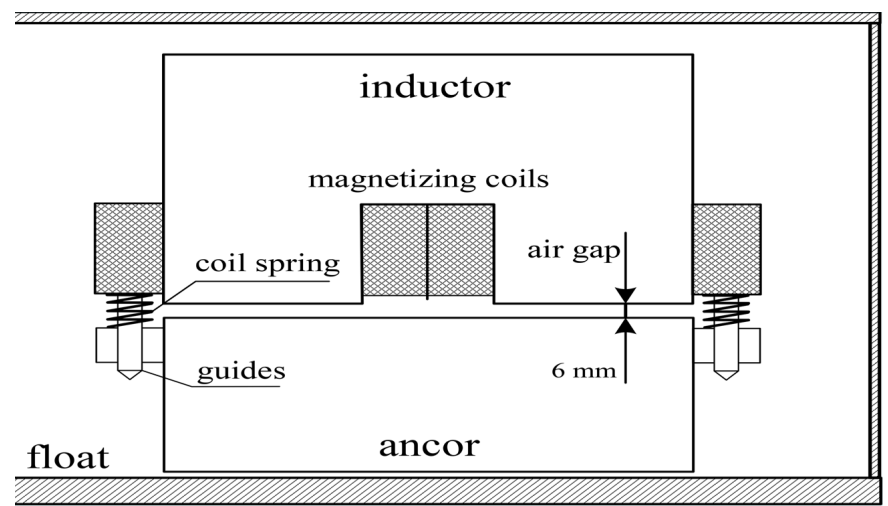

Fig. 1. The structural scheme of electromagnetic seismic source

interaction force $F_{\mathrm{EM}}[9]$ :

$$
F_{\mathrm{EM}}=B^{2} \cdot S_{\mathrm{P}} / 2 \mu_{0}
$$

where

$S_{\mathrm{P}}$ is the area of the poles of the magnetic circuit;

$\mu_{0}=4 \pi \cdot 10^{-7}$ is magnetic permeability of vacuum;

$B$ is magnetic field induction in the air gap $[\mathrm{T}]$.

A coil spring under the action of the force $F_{\mathrm{EM}}$ accumulates elastic energy, which is subsequently spent on the formation of a back half-wave with peak value of force $F_{0}$ directed downward. The design shown in Fig. 1 allows you to create distinctive features of an electromagnetic seismic source (EMSS) from the water sources presented, for example, the "Yenisei VEM-50":

- the exception of the inductor overranning the air gap $\delta$, during the formation of seismic signals;

- the exclusion of mechanical shock between an ancor and inductor;

- the possibility of forming a bipolar SA impact, allowing for more optimal coordination with the environment;

- the ability to generate vibrational signals with a frequency of up to $200 \mathrm{~Hz}$.

The listed advantages potentially expand the operational capabilities of the seismic source. We set the estimated values of the mass of the inductor $M_{r}$ (the reactive mass), and the mass of the emitter $M_{s}$ based on a simple ratio:

$$
M=\frac{F_{0} \cdot \tau^{2}}{2 \delta},
$$

where $\tau$ is pulse duration at the value of the applied force $F_{0}=12.5 \mathrm{kN}$.

To increase the energy transfering to the medium by source is necessary to select the dimension of the magnetic gap, which determines displacement of the plate $\delta_{\mathrm{s}}$ in a fixed reference frame matched with the medium. This displament is larger than similar displacement $\delta_{\mathrm{r}}$ of reactive mass of inductor $M_{r}$ at several times. The value $\tau=3 \mathrm{~ms}$ is based on the requirement to ensure the upper limit of the frequency range $f_{\max } \geqslant 150 \mathrm{~Hz}$ EMSS. We specify a value of delta, $\delta_{\mathrm{s}}=3 \delta_{\mathrm{r}}$, i.e. $\delta_{\mathrm{s}}=3 \mathrm{~mm}, \delta_{\mathrm{r}}=1 \mathrm{~mm}$. According to the expression (2) we obtain the reactive mass values 
$M_{\mathrm{r}}=112.5 \mathrm{~kg}$ and $M_{\mathrm{s}}=37.5 \mathrm{~kg}$ for the magnetization time $\tau=3 \mathrm{~ms}$. In this case, the acceleration of the inductor and source remitter plate are equal $a_{r}=111 \mathrm{~m} / \mathrm{s}^{2}$ and $a_{s}=333 \mathrm{~m} / \mathrm{s}^{2}$ respectively. The values of the maximum velocity of the active and reactive masses can be determined through the expression:

$$
V_{r}=\frac{a \cdot \tau^{2}}{2}
$$

According to the expression (3) $V_{r}=0.5 \mathrm{~m} / \mathrm{s}$ and $V_{s}=1.5 \mathrm{~m} / \mathrm{s}$. At the same time, a drag force to motion of the emitter plate is generated, from which linearity of response of the source structure to the impulse effect depends. Consider, this process in more detail. In the ideal case, with a constant modulo force $F_{0}$, the motion of the inductor will be uniformly accelerated (Fig. 2).

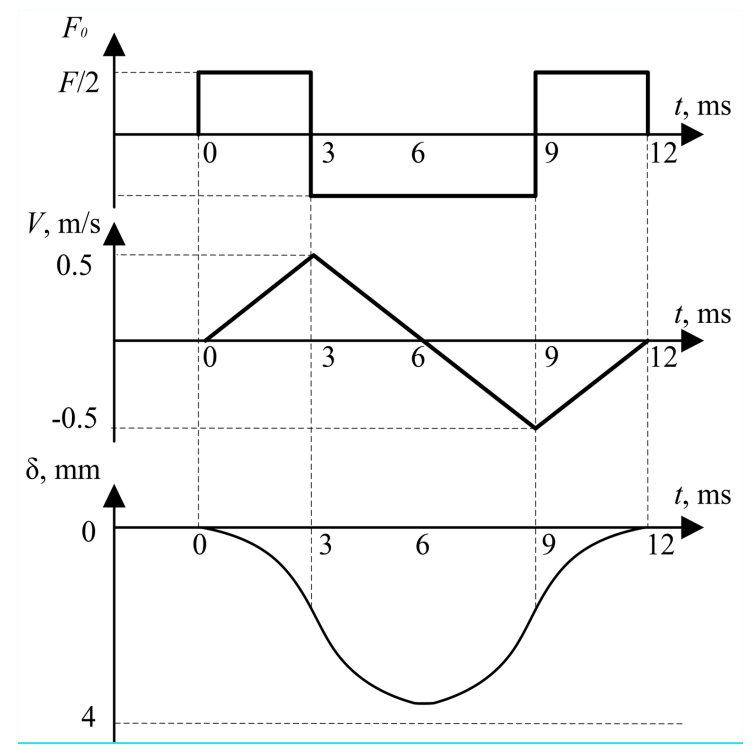

Fig. 2. Plots of the ideal mechanical impulse of a seismic source

Investigation of the linear nature of the motion of the emitter in water is of great practical importance. In this case, it requires a complex solution of nonlinear equations, which significantly complicates software and mathematical support of the seismic source control system. We introduce several restrictions for describing the motion of the emitter in water:

- the force $F_{0}$ remains constant at every moment of time and at every point of the trajectory of motion;

- the propagation medium is absolutely incompressible and isotropic;

- the geometric parameters of source exclude the appearance of cavitation and nonlinear processes at the interface "medium-source".

The equation of motion of the emitter surface includes all the forces that act on the plate during movement in the aquatic environment (Fig. 3):

$$
M \bar{a}=\overline{F_{0}}+\bar{R}+\overline{F_{A}}+m_{0} \bar{g},
$$


where

$\bar{a}$ is acceleration of the emitter plate;

$\overline{F_{0}}$ is external force acting on the emitter plate;

$\overline{F_{A}}$ is Archimede's buoyant force;

$\bar{g}$ is acceleration of gravity;

$m_{0}$ is plate mass;

$M=\left(m_{0}+M_{a d d}\right) ;$

$M_{a d d}$ is additional mass of water, formed in the half-space under the plate with dimensions $b \times b[10]:$

$$
M_{\mathrm{add}}=\frac{\pi}{4} \rho \frac{b^{2}}{\sqrt{2 b^{2}}}\left(1-0.425 \frac{b^{2}}{2 b^{2}}\right) .
$$

Then the equation (4) can be written in the differential form:

$$
M \frac{d V}{d t}=F_{0}-R
$$

where $V$ is instantaneous speed of emitter plate.

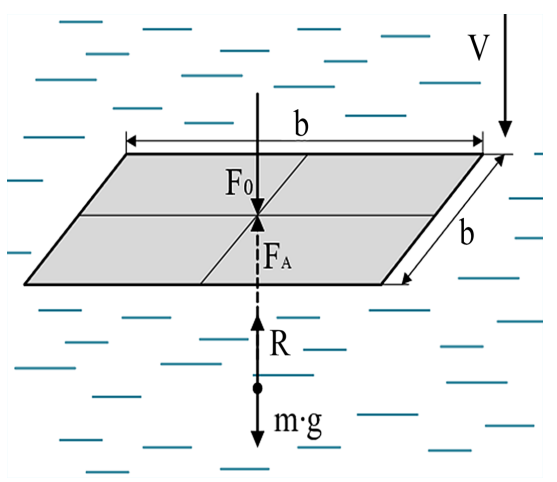

Fig. 3. The movement of the emitter plate in the water under the effect of electrodynamic forces

The hydrodynamic resistance of water during the movement of a emitter plate requires a separate analysis. When a body moves in a liquid at a low speed, the resistance to motion is $R$ determined by the friction force, which is proportional to the viscosity of the medium and the velocity of motion $V[11]$ :

$$
R \sim V
$$

With an increase in the velocity $V$, the resistance force is determined by the work on the formation of eddies.

$$
R=c_{x} \frac{\rho V^{2}}{2} S
$$

where

$\rho$ is density of medium;

$c_{x}$ is drag coefficient;

$S$ is area of the emitter plate.

To estimate the velocity, we turn to the concept of the Reynolds number $R e$, which determines the functional dependence of $c_{x}$ on the viscosity and density of the medium, the velocity of 
movement, and the linear dimensions of the source [8]:

$$
c_{x}=f(R e), \quad R e=\frac{2 r V}{v},
$$

where $v=\eta / \rho$ is kinematic viscosity of medium, $\eta \approx 10^{-2}$ is viscosity index for water.

From this we can conclude that the law of viscous friction for motion in water (7) is satisfied when $V r \leqslant 10^{-3}[12]$.

In our case, with the velocity modulus $|V| \leqslant 5 \mathrm{~m} / \mathrm{s}$ and section of the impact plate $S \leqslant 1 \mathrm{~m}^{2}$, the Reynolds number is of the highest order $R e>>1$, which indicates a predominantly quadratic dependence of $\mathrm{R}$ on $\mathrm{V}$ according to the expression (8) $R e \approx 10^{5}$. The drag coefficient is in the range of $1 \leqslant c_{x} \leqslant 1.28[10]$.

Given (8), the equation (3) can be represented as:

$$
M \frac{d V}{d t}=F_{0}(x)-c_{x} \frac{\rho s}{2} V^{2} .
$$

We consider the external impact force $F_{0}$ to be constant in absolute value over the entire range of displacement of the emitter plate along the axis $O X$. The conditional constancy of the force module $F_{0}$ is ensured by the source design, as well as by the algorithm of the control system of the exciting electromagnetic signal. With the reduction of the gap between the ancor and the inductor current amplitude changes accordingly involved in the formation of the $F_{E M}$. Also, the coil springs are in a constantly compressed state, which affects the stability of the external force, $F_{0}=$ const, i.e. the condition is satisfied:

$$
\frac{F_{0}}{k}>>\delta
$$

where $k$ is the spring stiffness, $\delta$ is the air gap (see Fig. 1).

Then, the equation (5) can be reduced to an ordinary first-order differential equation with separable variables:

$$
\frac{d V}{d t}=\underbrace{\left(\frac{F_{0}}{M}\right)}_{A}-\underbrace{\left(\frac{c_{x} \rho S}{2 M}\right)}_{B} V^{2} .
$$

The equation (12) can be written as:

$$
\frac{d V}{d t}=A-B V^{2},
$$

where $B=\frac{c_{x} \rho S}{2 M}, A=\frac{F_{0}}{M}$.

Separating the variables in the equation (13) and integrating, we obtain an equation relating the parameters $V$ and $t$ :

$$
t=\frac{1}{B}\left(\frac{1}{2 \sqrt{\frac{A}{B}}} \cdot \ln \left[\frac{V-\sqrt{\frac{A}{B}}}{V+\sqrt{\frac{A}{B}}}\right]\right)+C,
$$

where $C$ is the integration constant determined from the initial condition.

Considering that at the initial instant $t=0$ the system is atstate of rest, the initial condition has the form: $V(0)=0$, therefore, $C=0$. Express from (14) speed parameter $V$ through time parameter $t$. We introduce the following notation:

$$
q=\sqrt{\frac{A}{B}}, \quad Q=e^{-\left(2 \frac{B}{M} \sqrt{\frac{A}{B}}\right) t}
$$


Then the equation will have two symmetric solutions:

$$
\frac{V-q}{V+q}=Q, \quad \frac{V-q}{V+q}=-Q .
$$

Discarding the first solution, due to physical absurdity, we obtain the dependence of the speed of the base plate on time:

$$
V(t)=\frac{q(1-Q)}{(1+Q)}=\sqrt{\frac{A}{B}} \cdot \frac{1-e^{-t 2 B q}}{1+e^{-t 2 B q}} .
$$

Substituting the values in the expression (16) yields:

$$
A=\frac{F_{0}}{M}, \quad q=\sqrt{\frac{c_{x} \rho S}{2 F_{0}}}, \quad B=\frac{c_{x} \rho S}{2 M} .
$$

Given (5), we write the final equation describing the velocity of the emitter plate in the aquatic media:

$$
V(t)=\sqrt{\frac{2 F_{0}}{c_{x} \rho S}} \cdot \frac{1-e^{-t \sqrt{\frac{c_{x}^{3} \rho^{3} S^{3}}{2 F_{0}\left(m_{0}+M_{\mathrm{np}}\right)^{2}}}}}{1+e^{-t \sqrt{\frac{c_{x}^{3} \rho^{3} S^{3}}{2 F_{0}\left(m_{0}+M_{\mathrm{np}}\right)^{2}}}}} .
$$

Formula (18) we consider a mathematical model of the motion plate. The simulation results in the MatLab computing environment are presented in Fig. 4 in the form of graphs of the dependence $V(t)$ for different sizes of emitter surfaces under the action of a constant force $F_{0}=30 \mathrm{kN}$.

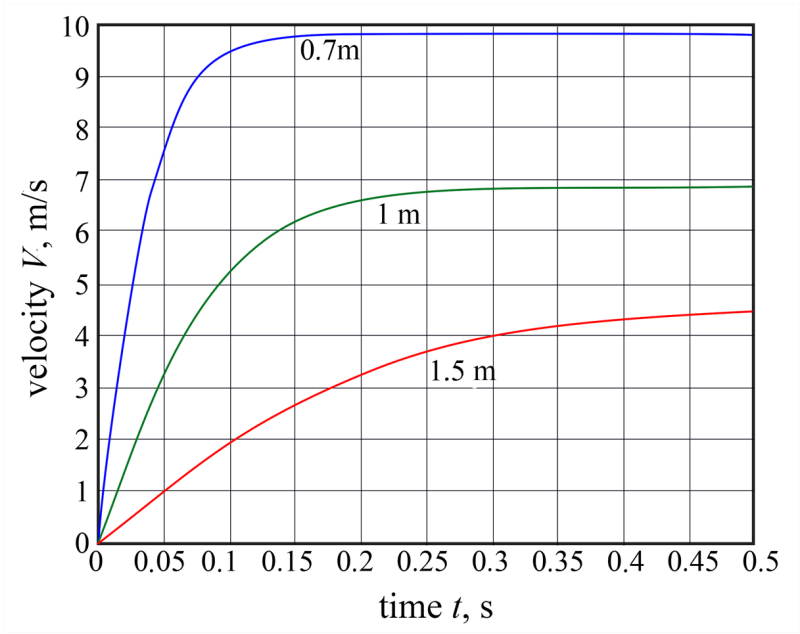

Fig. 4. Dependence of the speed of motion of a flat emitter surface $V$ VS $t$ under the action of a constant force and various sizes of the emitter plate

Dependence of the speed of motion of a flat emitter surface $V$ on time $t$ under the action of a constant force and various sizes of the emitter plate. The linear dependence in eq. (7) is observed at a given time interval for each of the plate sizes $b$ specified in the model and having practical application. Therefore, as a first approximation, we can achieve the desired shape of the pulse impact on the environment, as shown in Fig. 2. In the future, the model is subject to experimental verification according to the results of laboratory tests. 


\section{Conclusion}

Analysis of the seismic problems in an aqueous medium discovered benefit of using electromagnetic sources compared pneumatic or explosive sources of environmental parameter. Also, the analysis revealed the shortcomings of the used electromagnetic impulse seismic sources. The article provides a theoretical justification for the effectiveness of the use of EMC with bipolar excitation in comparison with seismic sources with an electromagnetic drive Yenisei, in particular the VEM-50 seismic source. In particular, an important result is the development of a mathematical model of the source in the aquatic environment, which describes the dependence of the motion of the emitter base plate in a liquid under the action of an external driving force. The results will be the basis for further research in the field of seismic exploration based on signals with a large base of $B \gg 1$ (orthonormal, or pseudonoise signal).

The reported study was funded by RFBR and the government of Krasnoyarsk region according to the research project no. 18-45-242003. "Research and development of methods for distance increasing of the geological sounding by seismoacoustic pseudonoise orthonormal sequences signals". The authors also thank the Siberian Federal University and "Evenkiyageofizika" OJSC for their help in organizing field studies at the geophysical training and testing ground.

\section{References}

[1] V.N.Semenov, Yu.I.Zuenko, I.A.Atamanova et al., Toolkit for assessing the extent of harm to aquatic biological resources in seismic and electrical exploration, Publishing house VNIRO, 2016 (in Russian).

[2] G.Ya.Shaidurov, D.S.Kudinov, A.A.Shchitnikov, Pulsed Non-Explosive Seismic Sources With an Electromagnetic Drive, International Journal of Applied Engineering Research, 10(2015), no. 15, 35907-35913 (in Russian).

[3] G.Ya.Shaidurov, D.S.Kudinov, System Mathematical Models for the Formation of Signals and Synchronous Interference with the use of pulsed non-explosive seismic sources, Journal of Siberian Federal University. Mathematics \& Physics, 8(2015), no. 4, 442-453 (in Russian).

[4] S.A.Zhgenti, Application of the latest seismic exploration technologies in shallow water and in transit zones objectively ensures the leadership of PGS-Khazard in the Russian market of geophysical services, Instruments and systems for exploration geophysics, 1(2012), no. 2, 23-26 (in Russian).

[5] V.A.Detkov, G.Y.Shaydurov, Pulse non-explosive sources for seismic exploration, 2011 International Siberian Conference on Control and Communications, SIBCON 2011, Vol. 1, 2011, 228-229 (in Russian).

[6] S.R.L.Tenghamn, Patent US No 20180128927 A1, Coded Signals for Marine Vibrators. PGS Geophysical AS, 10 may 2018.

[7] M.M.Benjamin, Encoding techniques for marine seismic sources \& their applications, Doctoral Thesis, 2016.

[8] N.Lund, O.C.Olgi, M.D.C.Oskarson, Patent CN No 107430203 A, Methods and systems to separate seismic data associated with impulsive and non-impulsive sources. Geophysical companies, 20 Oct. 2015. 
[9] O.B.Bull, Calculation methods for magnetic systems of electrical apparatus. Magnetic circuits, fields and the FEMM program. Textbook for universities in the specialty "Electrical and electronic devices" direction "Electrical Engineering, Electromechanics and Electrotechnology", Publishing House Academy, 2005 (in Russian).

[10] N.E.Kochin, I.A.Kibel, N.V.Rose, Theoretical hydromechanics, Gostekhizdat Publishing House, 1948 (in Russian).

[11] A.N.Sherstyuk, Fluid and gas dynamics: A Training Manual Institute of Continuing Education of SFU, 2009 (in Russian).

[12] L.G.Loitsyansky, Mechanics of fluid and gas. 6th ed., Publishing House Nauka, 1987 (in Russian).

\title{
Физические основы формирования энергетически квазиоптимального импульсного сейсмоакустического воздействия для геофизических исследований в условиях мелководья и транзитных зон. Часть 1. Теоретические основы
}

\author{
Данил С. Кудинов \\ Олег А. Майков \\ Институт нефти и газа \\ Сибирский федеральный университет \\ Свободный, 79, Красноярск, 660041 \\ Россия \\ Павел В. Баландин \\ ООО "Эвенкиягеофзика" \\ Республика, 173, Тюмень, 625023 \\ Россия
}

\footnotetext{
Несмотря на развитие альтернативной энергетики, углеводородное сырье является одним из важнейших энергетических ресурсов во всем мире. Открытие новых месторождений попрежснему актуалъная задача. Средне- и долгосрочные перспективы развития сейсморазведки принято связывать с освоением континентального шельфа, в частности арктического. Также большой сыръевой потенииал сегодня ожидается от малоизученных территорий, расположенных на арктическом побережье РФ, рифовых зонах государств персидского залива, а такэе в транзитной и мелководной зоне (на глубине до 10 м).

В статъе исследуются теоретические аспекты возбуждения сейсмоакустических (СА) волн в водной среде, рассматриваются проблемы аппаратурной реализации принципиально нового источника сейсмических колебаний, способного работать на акватории, в приливно-отливной и береговой зонах, т.е. производить непрерывное сейсмическое профилирование с акватории на сушу.

Ключевые слова: сейсмоисточник, сейсмоакустика, псевдослучайная последовательность, мелководъе, транзитная зона.
} 